\title{
I mpact of obstructive sleep apnea on aortic elastic properties and left ventricular functions in hypertensive and normotensive patients: Correlation with brain natriuretic peptide levels
}

\author{
Mohamed Fahmy Elnoamany, MD ${ }^{1}$, Ashraf Abdelraouf Dawood,MD², Mahmoud Mossa Elhabashy, \\ $M^{3}$, Yasser Abdelwahab Khalil, MD ${ }^{4}$
}

(1)Cardiology Department, (2)Biochemistry Department, (3)Chest Department, (4)Otolaryngology Department. Faculty of Medicine, Menoufiya University, Shebin El Kom, Egypt.

Correspondence: Mohamed Fahmy Elnoamany. Address: 11 Yossef Street from Talaat Harb Street, Shebin Elkom, Menoufyia, Egypt. Telephone: 002-010-661-3264. Fax: 002-048-232-5858. Email: mnoamany@hotmail.com

Received: March 19, 2012

DOI : $10.5430 /$ jbgc.v2n1p65
Accepted: May 15, 2012

Published: June 1, 2012

URL: http://dx.doi.org/10.5430/jbgc.v2n1p65

\section{Abstract}

Background: Obstructive sleep apnea syndrome (OSAS) has been linked to cardiovascular (CVS) complications. The diagnosis of effects of sleep apnea on heart may be difficult before apparent examination findings. Although the mechanisms underlying the association between OSAS and CVS disease are not known, it is believed that, the CVS effects of OSAS have a multifactorial pathogenesis.

Objectives: To evaluate aortic elastic properties and left ventricular (LV) functions in patients with OSAS with and without systemic hypertension (HTN) and correlate these findings with brain natriuretic peptide (BNP) levels.

Patients \& methods: The study comprised 133 patients and 30 age and sex matched healthy volunteers as a control group (Group I). The patients were divided according to the presence of OSAS and HTN into 3 groups; Group II (42 patients) with HTN, Group III (44 patients) with OSAS and Group IV (47 patients) with both HTN and OSAS. All subjects included in the study underwent polysomnography and echocardiography. Assessment of LV function (systolic and diastolic), aortic strain (AS), distensibility (AD) and aortic wall systolic velocity (AWSV) was done using conventional echocardiography and Doppler tissue imaging (DTI). BNP levels were measured within 2 hours of echocardiography by rapid immunoassay.

Results: Comparing control group to patients groups, AWSV $(8.5 \pm 1.5 \mathrm{~cm} / \mathrm{sec}$ vs. $6.04 \pm 2.4 \mathrm{~cm} / \mathrm{sec}, 6.1 \pm 1.9 \mathrm{~cm} / \mathrm{sec}$, $5.01 \pm 1.5 \mathrm{~cm} / \mathrm{sec}, p<0.001$ for each), AS (17.2 $\pm 9 \%$ vs. $11.7 \pm 4 \%, 8.7 \pm 5 \%, 8.7 \pm 4 \%, p<0.001$ for each) and $\mathrm{AD}(10 \pm 5$ $\mathrm{cm}^{2} /$ dyn $/ 10^{3}$ vs. $6 \pm 2 \mathrm{~cm}^{2} / \mathrm{dyn} / 10^{3}, 7 \pm 1 \mathrm{~cm}^{2} / \mathrm{dyn} / 10^{3}, 4 \pm 2 \mathrm{~cm}^{2} / \mathrm{dyn} / 10^{3}, p<0.01$ for each) were significantly lower in all patients groups than control subjects. Long axis LV systolic function and LV diastolic function parameters were significantly impaired in all patients groups compared to control group, whereas LV Tei index and BNP levels were significantly higher in patients in comparison to control subjects. AWSV, AD and AS have strong significant positive correlations with mitral annular plane systolic excursion (MAPSE) $(r=.61, r=.55, r=.41$ respectively, $p<0.01$ for each), Systolic mitral annular velocity $(\mathrm{Sm})(r=.64, r=.48, r=.47$ respectively, $p<0.001$ for each $)$, mitral inflow E/A ratio $(r=.49$, 
$r=.41, r=.39$ respectively, $p<0.05$ for each) and DTI-derived mitral annular Em/Am ratio $(r=.60, r=.45, r=.42$ respectively, $p<0.01$ for each) while the correlation was negative with Tei index $(r=-.61, r=-.5, r=-.45$ respectively, $p<0.01$ for each) and BNP levels $(r=-.67, r=-.59, r=-.5$ respectively, $p<0.001$ for each). In multivariate analysis, age, HTN, OSAS and LV mass index are the independent predictors for impaired aortic elasticity.

Conclusion: Aortic elasticity parameters (AWSV, AS and AD), Long axis LV systolic function (MAPSE and Sm), LV diastolic function parameters (derived by both conventional and tissue Doppler), Tei Index and BNP levels are all impaired in patients with OSAS, HTN or both. Accordingly subtle subclinical cardiac dysfunction is present in patients with OSAS independent from HTN.

\section{Key words}

Obstructive sleep apnea, Doppler tissue imaging, Left ventricular function, Aortic elasticity, Brain natriuretic peptide

\section{I ntroduction}

Obstructive sleep apnea syndrome (OSAS) is the most common form of sleep-disordered breathing, affecting thousands of patients each year ${ }^{[1,2]}$. It is characterized by repetitive partial or complete closure of the upper airway during sleep. Acute physiologic stresses occur during these episodes of asphyxia, including arterial oxygen desaturation, surges in sympathetic activity, and acute hypertension. In a patient with moderate-to-severe OSAS, these cycles may occur hundreds of times a night. Descriptions of sleep-disordered breathing date back nearly 200 years ${ }^{[3]}$, but only in the past 20 years have treatment options made diagnosis and intervention a priority ${ }^{[4]}$. The association between OSAS and cardiovascular (CVS) disease was first raised by observational studies linking snoring, a surrogate for OSAS, with increased cardiac events ${ }^{[5]}$. Subsequent studies have demonstrated a clear relationship between the presence and severity of OSAS and both systemic hypertension and increased CVS disease ${ }^{[6-8]}$. Currently, OSAS is thought to play a role in the pathogenesis of systemic hypertension and congestive cardiac failure, as well as possibly acute coronary syndromes, pulmonary hypertension, arrhythmias, and cerebrovascular events ${ }^{[9]}$.

There are several factors responsible for increased CVS morbidity and mortality in OSAS, such as systemic hypertension, pulmonary hypertension, impaired vascular endothelial function, ischemia, cardiac systolic and diastolic dysfunction, and tendency to arrhythmias ${ }^{[11]}$. Approximately $50 \%$ of patients with OSAS have systemic hypertension ${ }^{[12,13]}$. The pathogenetic link between OSAS and hypertension is not yet well understood. Although systemic hypertension may have a major role for occurrence of CVS complications, it is not the only mechanism for the long-term cardiac changes in OSAS and the disease itself also causes some abnormalities independent from hypertension ${ }^{[14,15]}$. Aortic elastic properties and aortic stiffness are important determinants of increased CVS morbidity and mortality in different diseases ${ }^{[16]}$. Aortic stiffness may influence the structure of the heart and cardiac systolic-diastolic functions. Assessing the relation between aortic stiffness and cardiac function parameters may be helpful for understanding the cardiac abnormality in patients with OSAS.

In clinical practice, the diagnosis of effects of sleep apnea on heart may be difficult before apparent examination findings. However, Doppler tissue imaging (DTI) is an echocardiographic technique which allows quantitative measurements of the myocardial contraction and relaxation velocities of a selected myocardial segment. This method can give important information on myocardial function in normal individuals and in patients with cardiac diseases ${ }^{[17]}$.

Brain natriuretic peptide (BNP) is a cardiac neurohormone secreted from the ventricles in response to ventricular volume expansion and pressure overload. BNP levels have been shown to be elevated in patients with asymptomatic and symptomatic LV dysfunction and correlate to disease severity and prognosis. BNP levels may also reflect diastolic dysfunction. It has been shown that BNP is useful in establishing or excluding diagnosis of heart failure in patients with acute dyspnea ${ }^{[18,19]}$.

The aim of this work is to evaluate aortic elastic properties and left ventricular functions in patients with OSAS with and without systemic hypertension and correlate these findings with BNP levels. 


\section{Patients and methods}

\section{Subjects}

The study enrolled 133 patients recruited from patients undergoing sleep study in the sleep disorders laboratory for suspected OSAS and 30 age and sex matched healthy volunteers as a control group (Group I). According to the presence or absence of OSAS (proven by sleep study) and systemic hypertension ( defined as arterial blood pressure more than 140/90 mm Hg or intake of antihypertensive medications), patients were divided into 3 groups; Group II (42 patients) with systemic hypertension, Group III (44 patients) with OSAS and Group IV (47 patients) with both systemic hypertension and OSAS. Patients were informed about the study protocol and written consent was obtained from each patient.

Exclusion criteria: patients with one or more of the following criteria, were excluded from the study:

1) Patients with diabetes mellitus.

2) Patients with ischemic heart disease.

3) Valvular heart disease.

4) Congenital heart disease.

5) Cardiomyopathies and LV ejection fraction $<60 \%$.

6) Previous stroke and patients with severe hypertension ( $\geq$ stage 3 ).

7) Chronic obstructive pulmonary disease.

8) Patients receiving oral contraception or hormone replacement therapy.

9) Aortic disease (eg, aneurysm, Marfan syndrome, coarctation, and aortic operation).

10) Patients with renal insufficiency.

11) Patients with poor echogenicity.

12) Patients with atrial fibrillation, ventricular premature contractions, and other arrhythmias.

13) Patients with conduction abnormalities e.g LBBB, RBBB, complete heart block.

14) Patients with pericardial effusion.

For each patient the following was done:

1) Complete history taking.

2) Thorough clinical evaluation.

3) Standard 12- lead resting Electrocardiogram (ECG).

4) Conventional echocardiographic examnation: Echocardiography was performed with the patient in the left lateral decubitus position. The equipment used was (Vivid S 5, GE- Vingmed Ultrasound AS system, Horten, Norway). Measurements were performed according to the recommendations of the American Society of Echocardiography ${ }^{20]}$ with the use of the long axis parasternal, apical 4, 5 and 2-chamber views. All patients underwent conventional $\mathrm{M}$ - mode (MM) and 2-D echocardiographic examination. Visual assessment of regional wall motion was performed. End systolic diameter (LVESD) and volume, end diastolic diameter (LVEDD) and volume (by manual tracing of endocardial borders) and left ventricular ejection fraction (LVEF) was calculated using Simpson's rule ${ }^{[21]}$. Conventional (continuous and pulsed) Doppler valvular flow was determined. Displacement of the mitral annulus was measured by MM from four different points (medial, lateral, anterior, inferior) by apical 
four-chamber and apical two-chamber approaches (see Figure 5). Analysis was performed for the average of mitral annular plane systolic excursion (MAPSE) measured at the four annular sites ${ }^{[22]}$.

5) Calculation of aortic elasticity parameters using M-mode: Aortic strain ${ }^{[23]}$ and distensibility ${ }^{[23,24]}$ were used as aortic elasticity parameters. The formulas used to calculate the above mentioned parameters were as follows: Aortic strain $(\%)=($ aortic systolic diameter - diastolic diameter $) \times 100 /$ diastolic diameter (see Figures 1, 2) Aortic Distensibility $\left(\mathrm{cm}^{2} /\right.$ dyn $)=(2 \times$ aortic strain $) /($ systolic pressure - diastolic pressure $)$.

6) Doppler tissue imaging (DTI) Examination: DTI of the mitral annulus was obtained from the apical (2- and 4-chamber) views after filters were set to exclude high-frequency signals. A 5-mm sample volume was placed sequentially at the medial, lateral, inferior and anterior mitral annuli (see Figure 6). The resulting velocities were recorded for 3 consecutive cardiac cycles at a sweep speed of $100 \mathrm{~mm} / \mathrm{s}$. The following measurements were made from the recordings: peak systolic velocity (Sm), early (Em) and late (Am) diastolic velocities. Analysis was performed for the average of each velocity wave measured at the four annular sites. DTI-derived isovolumic contraction time (tICT) was measured between cessation of A wave and onset of S wave; DTI-derived ejection time (tET) was obtained between onset and cessation of S wave; DTI-derived isovolumic relaxation time (tIRT) was obtained between cessation of $\mathrm{S}$ wave and onset of $\mathrm{E}$ wave. Tei index ${ }^{[25]}$ was calculated as $(\mathrm{tICT}+\mathrm{tIRT}) /(\mathrm{tET})$.

All Doppler echocardiographic and DTI recordings were obtained during normal respiration. The data were stored for subsequent playback, measurement and analysis. All echocardiograms were interpreted by experienced cardiologist who was blinded to BNP levels ${ }^{[22]}$.

Pulsed-wave Doppler tissue imaging (PWDTI) of aortic wall: By switching into the DTI mode, systolic and diastolic velocity profile can be depicted from both anterior and posterior aortic walls. The peak aortic wall systolic (AWSV) and peak early diastolic (AWDV) aortic wall velocities were recorded by placing the sample volume of PWDTI mode on the anterior then the posterior aortic wall in the parasternal long axis view about 2-3 $\mathrm{cm}$ above the aortic valve (see Figure 3). The time required for maximum systolic aortic root expansion (prior to the aortic valve opening) is the time to peak velocity in systole (TS), it is measured from the isometric contraction wave to the peak $\mathrm{S}$ wave (see Figure 4). The time from peak expansion to baseline dimension in diastole is the time to peak early diastolic velocity (TD). It is measured from the isometric relaxation wave to the peak of $\mathrm{E}$ wave.

The AWSV, AWDV, TS and TD were measured in each subject and compared to aortic distensibility derived from conventional MM echo and simultaneous blood pressure recordings. The mean of 3 consecutive cardiac cycles from each wall was taken and the mean value from both walls then calculated ${ }^{[26]}$.

7) Overnight polysomnography (PSG): is performed using (Embla S 4000 Medcare, Iceland). It is conducted in the sleep laboratory, Menoufyia University Hospital. All groups were examined with polysomnography (PSG) according to the data of the apnea-hypopnea index (AHI).

The system has the following components:

- Somnologica studio 3.3.2 software.

- Pulse oximetery sensor (oximeter flex sensor 8000J).

- Airflow nasal pressure cannula.

- Airflow thermistor.

- Respiratory inductive plethysmography (RIP) belts with thoracic and abdominal locks. 
- Snoring microphone (piezo snoring sensor).

- Body position sensor.

- Electroencephalogram (EEG) electrodes with their cables.

- Electro-oculogram (EOG) electrodes.

- Electromyogram (EMG) electrodes for the chin and anterior tibialis muscle.

- Electrocardiogram (ECG) electrodes with their cables.

The system records the following parameters:

- Sleep stages: a) EEG through four channels to identify sleep stages, sleep latency and arousals. b) EOG for documentation of the onset of rapid eye movement (REM) sleep and the presence of slow-rolling eye movements that usually accompany the onset of sleep. c) Submental EMG to record atonia during REM sleep or lack of atonia in patients with REM-related parasomnias. Sleep has traditionally been scored from these variables using modifications of the rules developed by Rechtschaffen and Kales ${ }^{[27]}$. In addition, arousals from sleep can be determined using the criteria set by the American Sleep Disorders Association ${ }^{[28]}$.

- Airflow changes: using a thermistor that sense alterations in heat exchange and nasal prongs connected to a sensitive pressure transducer.

- Respiratory effort: using respiratory inductive plethysmography (RIP) belts around the chest and abdomen that can detect changes in lung volumes with respiration.

- Changes in arterial oxygen saturation: Alterations in oxygen saturation can be detected using a pulse oximeter attached to the finger.

- Body position: Body position indicator was fixed to the front of the patient abdomen. It records the percent of time of the study spent in each of the four body positions (supine, prone, left or right lateral positions).

- Limb movements: are monitored using the anterior tibialis EMG activity of both legs.

- ECG: To record a modified lead II ECG, one electrode is placed approximately 3-5 cm (two finger widths) below the right clavicle. The other electrode is placed on the left lower ribcage.

Apneas were defined as complete cessation of airflow 10 seconds or longer. Hypopneas were defined as reduction of greater than $50 \%$ in 1 of 3 respiratory signals, airflow signal or either respiratory or abdominal signals of respiratory inductance plethysmography, with an associated decrease of $3 \%$ or more in oxygen saturation or an arousal. The AHI was defined as the number of apneas and hypopneas per hour of sleep. Patients with AHI of 5 or more were considered to have OSAS. In patients with AHI less than 5 , the diagnosis of OSAS was excluded ${ }^{[28]}$.

8) Measurement of BNP levels: All samples were collected by venipuncture into EDTA tubes within 2 hours of obtaining the echocardiogram. The blood samples were kept at room temperature and analyzed within 4 hours of sampling using the Triage BNP assay (Biosite diagnostics). In some cases, the sample was centrifuged and the plasma was frozen for 1 to 2 days at $-70^{\circ} \mathrm{C}$. Before analysis, each tube was inverted several times to ensure homogeneity. The BNP assay was a sandwich immunoassay that consisted of a disposable device to which 250 $\mu \mathrm{L}$ of EDTA-anticoagulated whole blood or plasma was added. The Triage meter was used to measure the BNP concentration by detecting a fluorescent signal that reflected the amount of BNP in the sample. Once $250 \mu \mathrm{L}$ of whole blood or plasma was added to the device, the cells were separated from the plasma by a filter, and the 
plasma containing BNP entered a reaction chamber that contained fluorescent-tagged BNP antibodies to form a reaction mixture. The reaction mixture was incubated for 2 minutes and then migrated through the diagnostic lane by capillary action to a zone of immobilized antibody that would bind the desired BNP-fluorescent antibody complex. The unbound fluorescent antibodies were washed away by excess sample fluid. After 15 minutes, the device was placed into the Triage meter, which measured the fluorescence intensity of the BNP assay zone. The Triage meter then correlated the fluorescence measurement to BNP concentration by use of an internal calibration curve. The assay was completed in 15 minutes. The precision, analytical sensitivity, interferences, and stability have all been previously described ${ }^{[29]}$.

Control Group: Thirty healthy normal volunteers with no evidence of hypertension, diabetes, or any other known cause of heart disease were identified as the control group. In this group, LVEF, Doppler recordings of the mitral inflow, MM and PWDTI data (from each of 4 mitral annular sites inferior, anterior, septum and lateral) were obtained with evaluation of aortic elasticity parameters, also BNP levels were estimated in the same manner like the patients group. These data were used as reference values.

Statistical Analysis: Data were analyzed by SPSS statistical package version 11.0 (SPSS Inc, Chicago, IL, USA). Quantitative data were expressed as mean and standard deviation (SD). Comparisons between means were evaluated by unpaired $t$-test or ANOVA (F) test (with post hoc test) for continuous variables with determination of the least significant difference (LSD) by pair wise comparison between group means, and by chi-square test for proportions. Pearson correlation coefficient $(r)$ was used to measure association between two quantitative variables. Level of significance was set as $P$ value $<0.05^{[30]}$.
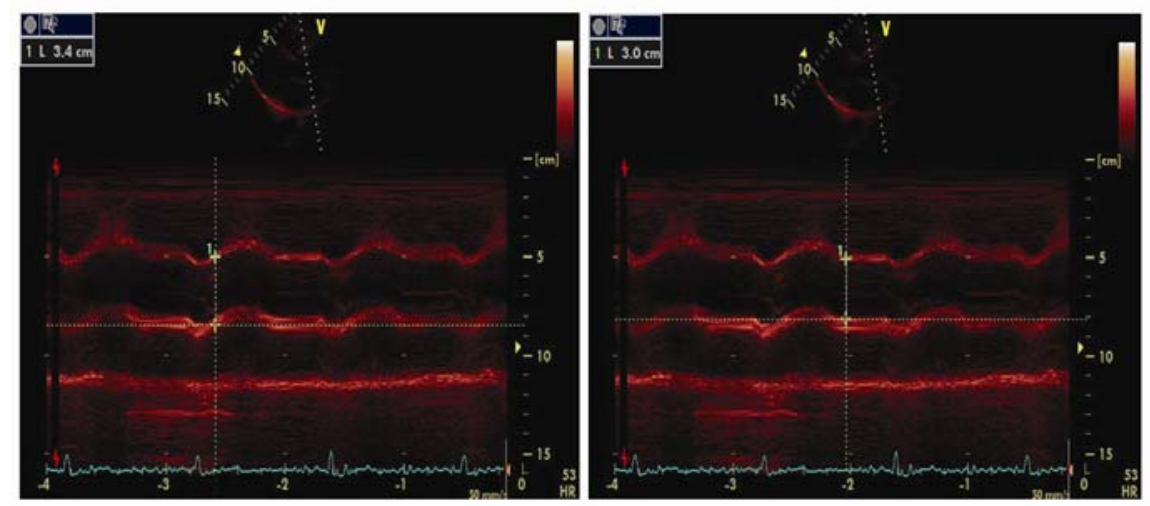

Figures 1 and 2. Example of a patient in group IV showing measurement of aortic systolic diameter (left) \& aortic diastolic diameter (right).
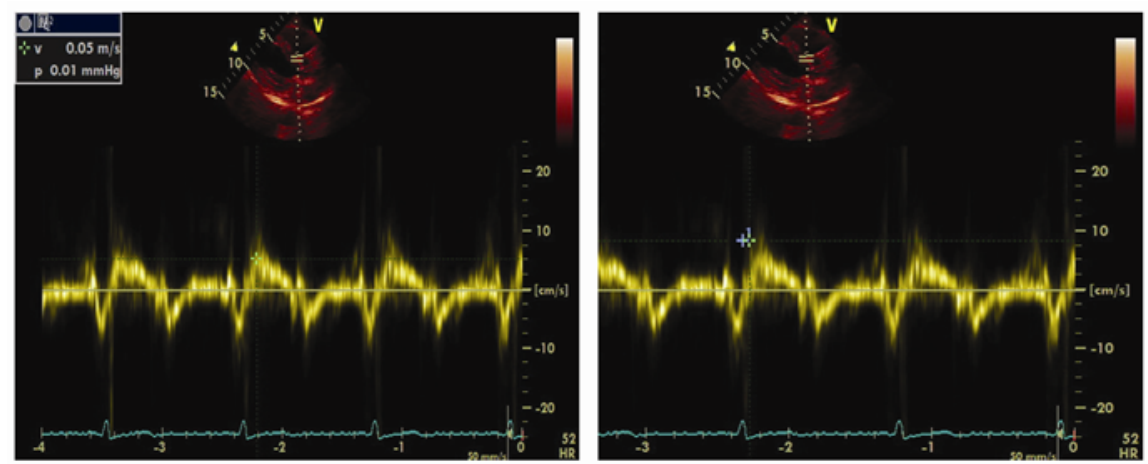

Figures 3 and 4. Measurement of aortic wall systolic velocity (left) \& time to peak systolic velocity (right) by Doppler tissue imaging in the same patient 

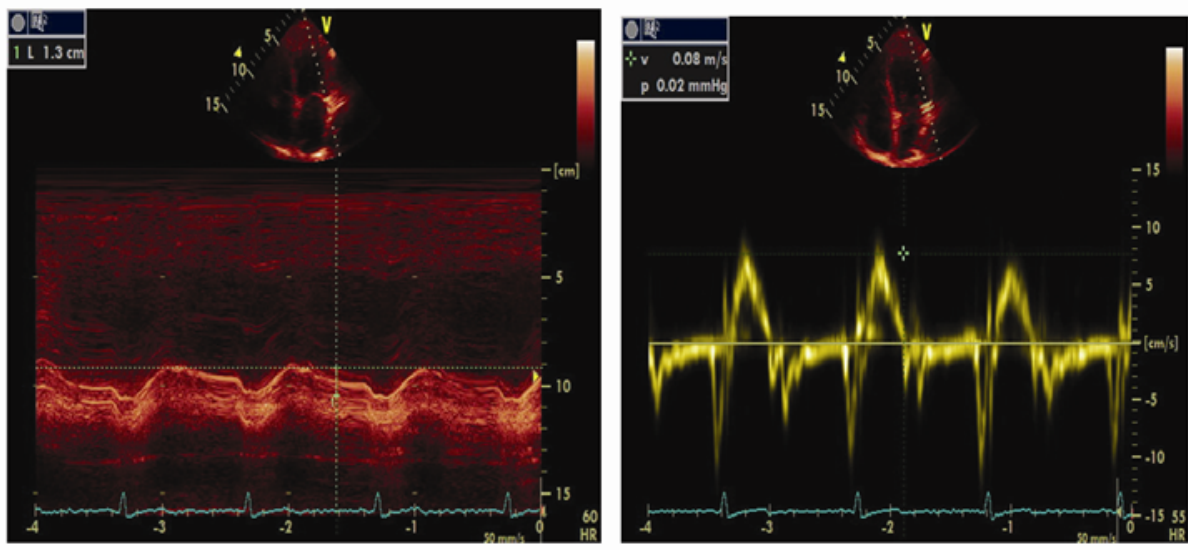

Figures 5 and 6. Measurement of mitral annular plane systolic excursion (MAPSE) by M-mode (left) \& mitral annular systolic velocity (Sm) by Doppler tissue imaging (right) at the lateral mitral annulus in the same patient

\section{Results}

The current study included 133 patients and 30 age and sex matched healthy volunteers as a control group (Group I), the control group included ( 25 males \& 5 females with mean age $46.1 \pm 5.1$ years). According to the presence or absence of OSAS (proven by sleep study) and systemic hypertension ( defined as arterial blood pressure more than 140/90 $\mathrm{mm} \mathrm{Hg}$ or intake of antihypertensive medications), patients were divided into 3 groups; Group II (42 patients) with systemic hypertension included ( 32 males \& 10 females with mean age $49.1 \pm 3.7$ years), Group III (44 patients) with OSAS included (35 males \& 9 females with mean age 51.1 4.9 years) and Group IV (47 patients) with both systemic hypertension and OSAS included (36 males \& 11 females with mean age 54.1 5.4 years) (see Table 1).

There was no significant difference between patients and control regarding age or sex $(p>0.05)$.

As regard the cardiovascular risk factors, no significant difference was found between patients and control group as regard body mass index, current smoking and heart rate $(p>0.05)$ (see Table 1$)$.

Systolic blood pressure, diastolic blood pressure and pulse pressure were significantly higher in each of group II and IV in comparison to group I and III $(p<0.05)$ (see Table1).

Total cholesterol levels and AHI were significantly higher in each of group III \& IV in comparison to control group and group II ( $p<0.05 \& p<0.001$ respectively). BNP levels were significantly higher in each of the patients groups in comparison to control group and in group IV compared to each of group II and III, $p<0.001$ (see Table1).

There was no significant difference between patients and control regarding LVEDD, LVESD and LVEF ( $p>0.05$ ) (see Table 2).

IVS and LVPW were significantly higher in group II and group IV in comparison to group I. LV mass index, deceleration time, IVRT were significantly higher in each of the patients groups compared to control group furthermore, IVRT was found significantly higher in group IV in comparison to each of group II and group III, $(p<0.05)$ (see Table 2$)$.

E/A ratio, MAPSE, Sm, Em and Em/Am ratio were significantly lower in each of the patients groups in comparison to control group. Also MAPSE, and Em/Am ratio were significantly lower in group IV in comparison to each of group II and group III (see Table 2). 
Table 1. Baseline demographic, clinical \& laboratory data of the studied groups

\begin{tabular}{|c|c|c|c|c|c|}
\hline Items & Group I $(n=30)$ & Group II $(n=42)$ & Group III $(n=44)$ & Group IV $(n=47)$ & $P$ value \\
\hline Age (years) & $46.1 \pm 5.1$ & $49.1 \pm 3.7$ & $51.1 \pm 4.9$ & $54.1 \pm 5.4$ & NS \\
\hline $\begin{array}{l}\text { Sex } \\
\text { (male/female) }\end{array}$ & $25 / 5$ & $32 / 10$ & $35 / 9$ & $36 / 11$ & NS \\
\hline $\mathrm{BMI}\left(\mathrm{Kg} \cdot \mathrm{m}^{2}\right)$ & $30 \pm 4$ & $30 \pm 6$ & $31 \pm 5$ & $31 \pm 6$ & NS \\
\hline Smokers & 4 & 5 & 5 & 6 & NS \\
\hline HR (beats /m) & $78 \pm 9$ & $80 \pm 10$ & $83 \pm 8$ & $83 \pm 7$ & NS \\
\hline $\begin{array}{l}\text { Systolic BP } \\
(\mathrm{mm} \mathrm{Hg})\end{array}$ & $120 \pm 12$ & $165 \pm 13^{*}$ & $121 \pm 10$ & $169 \pm 11^{*}$ & $p<0.05$ \\
\hline $\begin{array}{l}\text { Diastolic BP } \\
(\mathrm{mm} \mathrm{Hg})\end{array}$ & $80 \pm 10$ & $105 \pm 13^{*}$ & $85 \pm 11$ & $110 \pm 14^{*}$ & $p<0.05$ \\
\hline $\begin{array}{l}\text { Pulse pressure } \\
(\mathrm{mm} \mathrm{Hg})\end{array}$ & $40 \pm 7$ & $60 \pm 11^{*}$ & $36 \pm 9$ & $59 \pm 8^{*}$ & $p<0.05$ \\
\hline AHI & $2.3 \pm 0.5$ & $2.6 \pm 0.6$ & $29 \pm 15^{* \#}$ & $39 \pm 19^{*} \#$ & $p<0.001$ \\
\hline $\begin{array}{l}\text { Total } \\
\text { cholesterol } \\
(\mathrm{mg} / \mathrm{dl})\end{array}$ & $188 \pm 22$ & $195 \pm 25$ & $221 \pm 10^{*} \#$ & $232 \pm 11 * \#$ & $p<0.05$ \\
\hline $\mathrm{BNP}(\mathrm{pg} / \mathrm{ml})$ & $13.3 \pm 5.8$ & $221.2 \pm 49.1 *$ 少 & $233.7 \pm 55.1^{*} \frac{\|}{\pi}$ & $571.5 \pm 79.7 *$ & $p<0.001$ \\
\hline
\end{tabular}

Note. BMI, body mass index; HR, heart rate; BP, blood pressure; AHI, apnea-hypopnea index; BNP, brain natriuretic peptide; NS, non-significant; * , Control group vs. patients groups ; \#, Group II vs. other groups; 步, Group IV vs. other groups.

Table 2. Conventional echocardigraphic and Doppler tissue imaging data of the studied groups

\begin{tabular}{|c|c|c|c|c|c|}
\hline Items & Group I $(n=30)$ & Group II $(n=42)$ & Group III $(n=44)$ & Group IV $(n=47)$ & $P$ value \\
\hline LVEDD (mm) & $44.1 \pm 7.1$ & $45 \pm 6.7$ & $46.1 \pm 5.5$ & $47.3 \pm 5.4$ & NS \\
\hline LVESD (mm) & $27.3 \pm 5.2$ & $26.2 \pm 7.1$ & $28.1 \pm 6.3$ & $28.7 \pm 4.3$ & NS \\
\hline $\operatorname{IVS}(\mathrm{mm})$ & $9.1 \pm 1.9$ & $14.7 \pm 2.5^{*}$ & $10.3 \pm 1.9$ & $14.5 \pm 2.3^{*}$ & $p<0.05$ \\
\hline LVPW(mm) & $8.9 \pm 2.1$ & $13.9 \pm 2.2^{*}$ & $9.9 \pm 1.7$ & $14.1 \pm 1.1^{*}$ & $p<0.05$ \\
\hline LVEF (\%) & $68 \pm 6$ & $71 \pm 5$ & $69 \pm 7$ & $69 \pm 6$ & NS \\
\hline LVMI $g / \mathrm{m}^{2}$ & $80 \pm 19$ & $120 \pm 22 *$ & $111 \pm 27^{*}$ & $115 \pm 18^{*}$ & $p<0.05$ \\
\hline $\mathrm{E}(\mathrm{cm} / \mathrm{s})$ & $90 \pm 18$ & $75 \pm 22$ & $71 \pm 20$ & $50 \pm 21^{*}$ & $p<0.001$ \\
\hline $\mathrm{A}(\mathrm{cm} / \mathrm{s})$ & $65 \pm 16$ & $77 \pm 19$ & $75 \pm 17$ & $80 \pm 13^{*}$ & $p<0.05$ \\
\hline $\mathrm{E} / \mathrm{A}$ & $1.4 \pm 0.22$ & $0.9 \pm 0.09 *$ & $0.9 \pm 0.04 *$ & $0.6 \pm 0.19 *$ & $p<0.01$ \\
\hline Deceleration (ms) & $179 \pm 19$ & $230 \pm 21^{*}$ & $219 \pm 17 *$ & $228 \pm 23^{*}$ & $p<0.05$ \\
\hline IVRT (ms) & $85 \pm 13$ & $99 \pm 19^{*}$ 少 & $95 \pm 14^{*}$ 少 & $117 \pm 12 *$ & $p<0.05$ \\
\hline MAPSE (mm) & $17.9 \pm 2.1$ & $15.1 \pm 1.1 *$ 少 & $15 \pm 1.4^{*}$ 少 & $13.1 \pm 0.9^{*}$ & $p<0.05$ \\
\hline $\mathrm{Sm}(\mathrm{cm} / \mathrm{s})$ & $9.1 \pm 2.2$ & $8.1 . \pm 1.1^{*}$ & $7.9 \pm 1.3^{*}$ & $7.7 . \pm 1.3^{*}$ & $p<0.05$ \\
\hline $\operatorname{Em}(\mathrm{cm} / \mathrm{s})$ & $16.1 \pm 3.2$ & $9.1 . \pm 1.7^{*}$ & $8.9 \pm 1.4^{*}$ & $8.7 . \pm 1.3^{*}$ & $p<0.01$ \\
\hline $\operatorname{Am}(\mathrm{cm} / \mathrm{s})$ & $10.2 \pm 1.1$ & $9.9 . \pm 1.3$ & $9.8 \pm 1.5$ & $11.3 \pm 2.3^{*}$ & $p<0.05$ \\
\hline $\mathrm{Em} / \mathrm{Am}$ & $1.6 \pm 0.3$ & $0.9 . \pm 0.4 *$ 나 & $0.9 \pm 0.3 *$ 茫 & $0.8 \pm 0.2^{*}$ & $p<0.01$ \\
\hline Tei Index & $0.40 \pm 0.02$ & $0.54 \pm 0.01 *$ 少 & $0.53 \pm 0.03 *$ 少 & $0.62 \pm 0.07^{*}$ & $p<0.05$ \\
\hline $\begin{array}{l}\text { Diastolic } \\
\text { dysfunction } n(\%)\end{array}$ & $2(7 \%)$ & 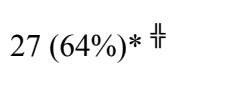 & 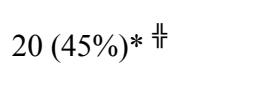 & $33(70 \%)^{*}$ & $p<0.05$ \\
\hline
\end{tabular}

Note. LVEDD, left ventricular end diastolic dimension; LVESD, left ventricular end systolic dimension; IVS, interventricular septum; LVPW, left ventricular posterior wall; LVEF, left ventricular ejection fraction; LVMI, left ventricular mass index; E, early diastolic wave; A, late diastolic wave; IVRT, isovolumic relaxation time; MAPSE, mitral annular plane systolic excursion; Sm, systolic mitral annular velocity; Em, early diastolic mitral annular velocity; Am, late diastolic mitral annular velocity; n, number; NS, non-significant; *, Control group vs. patients groups ; 坚 ,Group IV vs. other groups.

Tei index was significantly higher in each of the patients groups in comparison to control group and in group IV in comparison to each of group II and group III $(p<0.05)$ (see Table 2$)$. 
As regard the prevalence of LV diastolic dysfunction, it was detected in 2 patients (7\%) in group I, 27 patients (64\%) in group II, 20 patients (45\%) in group III, 33 patients $(70 \%)$ in group IV. The percentage of patients having diastolic dysfunction was significantly higher in each of the patients groups compared to control group furthermore, it was significantly higher in group IV in comparison to each of group II and group III $(p<0.05)$ (see Table 2).

As regard aortic stiffness parameters, There was no significant difference between all study groups as regard the aortic systolic diameter, whereas aortic diastolic diameter was significantly lower in control group compared to each of the patients groups $(p<0.01)$ (see Table 3 ).

Table 3. Aortic stiffness parameters in the study groups

\begin{tabular}{|c|c|c|c|c|c|}
\hline & Group I (n = 30) & Group II (n = 42) & Group III $(n=44)$ & Group IV (n = 47) & $P$ value \\
\hline $\begin{array}{l}\text { Pulse pressure } \\
(\mathrm{mmHg})\end{array}$ & $40 \pm 7$ & $60 \pm 11 *$ & $36 \pm 9$ & $59 \pm 8^{*}$ & $p<0.05$ \\
\hline $\operatorname{ASD}(\mathrm{cm})$ & $3.25 \pm 0.38$ & $3.6 \pm 0.26$ & $3.41 \pm 0.66$ & $3.59 \pm 0.36$ & $>0.05$ \\
\hline $\operatorname{ADD}(\mathrm{cm})$ & $2.81 \pm 0.37$ & $3.21 \pm 0.26^{*}$ & $3.15 \pm 0.65^{*}$ & $3.29 \pm 0.30^{*}$ & $<0.01$ \\
\hline $\mathrm{PDC}(\mathrm{cm})$ & $0.47 \pm 0.25$ & $0.38 \pm 0.13 *$ & $0.27 \pm 0.11 *$ & $0.29 \pm 0.16^{*}$ & $<0.01$ \\
\hline Aortic strain (\%) & $17.2 \pm 9$ & $11.7 \pm 4 *$ & $8.7 \pm 5^{*}$ & $8.7 \pm 4 *$ & $<0.001$ \\
\hline $\begin{array}{l}\text { Aortic distensibility } \\
\left(\mathrm{cm}^{2} / \mathrm{dyn} / 10^{3}\right)\end{array}$ & $10 \pm 5$ & $6 \pm 2 *$ 少 & $7 \pm 1 *$ 少 & $4 \pm 2 *$ & $<0.01$ \\
\hline AWSV $(\mathrm{cm} / \mathrm{sec})$ & $8.5 \pm 1.5$ & 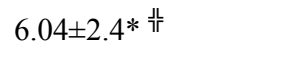 & $6.1 \pm 1.9 *$ 少 & $5.01 \pm 1.5^{*}$ & $<0.001$ \\
\hline TS (msec) & $14 \pm 1$ & $8.5 \pm 1 *$ & $8.6 \pm 1 *$ & $8.1 \pm 1^{*}$ & $<0.001$ \\
\hline AWDV $(\mathrm{cm} / \mathrm{sec})$ & $10.5 \pm 1.7$ & $7.52 \pm 1.5^{*}$ & $8.06 \pm 2.7^{*}$ & $7.05 \pm 1.7 *$ & $<0.001$ \\
\hline TD (msec) & $15 \pm 1$ & $10 \pm 1^{*}$ & $10 \pm 1 *$ & $12 \pm 4 *$ & $<0.001$ \\
\hline
\end{tabular}

Note. ASD: aortic systolic diameter; ADD: aortic diastolic diameter; PDC: pulsatile diameter change; AWSV: aortic wall systolic velocity; TS: time to peak systole; AWDV: aortic wall diastolic velocity; TD: time to peak early diastolic velocity. ;*, Control group vs. patients groups; 步, Group IV vs. other groups.

Table 4. Correlation between aortic stiffness parameters in patients groups and some echocardiographic, clinical and laboratory parameters

\begin{tabular}{|c|c|c|c|c|c|c|c|c|c|c|c|c|c|c|}
\hline & \multicolumn{2}{|c|}{$\begin{array}{l}\text { Aortic } \\
\text { Strain }\end{array}$} & \multicolumn{2}{|c|}{$\begin{array}{l}\text { Pulse } \\
\text { pressure }\end{array}$} & \multicolumn{2}{|c|}{$\begin{array}{l}\text { Aortic } \\
\text { distensibility }\end{array}$} & \multicolumn{2}{|c|}{ AWSV } & \multicolumn{2}{|l|}{ TS } & \multicolumn{2}{|c|}{ AWDV } & \multicolumn{2}{|l|}{ TD } \\
\hline & $r$ & $p$ & $r$ & $p$ & $r$ & $p$ & $r$ & $p$ & $r$ & $p$ & $r$ & $p$ & $r$ & $p$ \\
\hline MAPSE & .41 & $<0.01$ & -.37 & $<0.01$ & .55 & $<0.001$ & .61 & $<0.01$ & .46 & $<0.05$ & .03 & $>0.05$ & .01 & $>0.05$ \\
\hline $\mathrm{Sm}$ & .47 & $<0.05$ & -.36 & $<0.05$ & .48 & $<0.001$ & 0.64 & $<0.001$ & .49 & $<0.05$ & .11 & $>0.05$ & .21 & $>0.05$ \\
\hline LVEF\% & .24 & $>0.05$ & -.23 & $>0.05$ & .34 & $<0.05$ & .37 & $<0.05$ & .11 & $>0.05$ & .20 & $>0.05$ & .09 & $>0.05$ \\
\hline LVMI & -.1 & $>0.05$ & .01 & $>0.05$ & -.04 & $>0.05$ & -.47 & $<0.001$ & -.03 & $>0.05$ & -.03 & $>0.05$ & -.12 & $>0.05$ \\
\hline $\mathrm{E} / \mathrm{A}$ & .39 & $<0.05$ & -.27 & $>0.05$ & .41 & $<0.05$ & 0.49 & $<0.05$ & .35 & $<0.05$ & .09 & $>0.05$ & .21 & $>0.05$ \\
\hline $\begin{array}{l}\text { Decelaration } \\
\text { time }\end{array}$ & -.25 & $>0.05$ & .20 & $>0.05$ & -.29 & $>0.05$ & -0.32 & $>0.05$ & -.35 & $>0.05$ & -.01 & $>0.05$ & -.18 & $>0.05$ \\
\hline IVRT & -.11 & $>0.05$ & .19 & $>0.05$ & -.18 & $>0.05$ & -0.22 & $>0.05$ & -.23 & $>0.05$ & -.05 & $>0.05$ & -.17 & $>0.05$ \\
\hline $\mathrm{Em} / \mathrm{Am}$ & .42 & $<0.01$ & -.29 & $>0.05$ & .45 & $<0.01$ & 0.60 & $<0.01$ & .41 & $<0.05$ & .17 & $>0.05$ & .25 & $>0.05$ \\
\hline Tei Index & -.45 & $<0.01$ & .39 & $<0.05$ & -.5 & $<0.01$ & -0.61 & $<0.01$ & -.49 & $<0.05$ & -.21 & $>0.05$ & -.26 & $>0.05$ \\
\hline AHI & -.39 & $<0.05$ & .31 & $<0.05$ & -.43 & $<0.05$ & -0.55 & $<0.05$ & -.51 & $<0.05$ & -.19 & $>0.05$ & -.23 & $>0.05$ \\
\hline BNP & -.5 & $<0.001$ & .47 & $<0.05$ & -.59 & $<0.001$ & -0.67 & $<0.001$ & -.5 & $<0.05$ & -.23 & $>0.05$ & -.28 & $>0.05$ \\
\hline
\end{tabular}

Note. LVEF, left ventricular ejection fraction; LVMI, left ventricular mass index; E, early diastolic wave; A, late diastolic wave; IVRT, isovolumic relaxation time; MAPSE, mitral annular plane systolic excursion; Sm, systolic mitral annular velocity; Em, early diastolic mitral annular velocity; Am, late diastolic mitral annular velocity; AHI, apnea-hypopnea index; BNP, brain natriuretic peptide; AWSV, aortic wall systolic velocity; TS, time to peak systole; AWDV: aortic wall early diastolic velocity; TD: time to peak early diastolic velocity.

Pulsatile diameter change (PDC), Aortic strain, distensibility, aortic wall systolic velocity (AWSV), time to peak systole (TS), aortic wall diastolic velocity (AWDV), time to diastole (TD), were all significantly lower in each of the patients groups in comparison to the control group (see Table 3). 
Furthermore, aortic distensibility and AWSV were significantly lower in group IV compared to each of group II and group III $(p<0.01 \& p<0.001$ respectively) (see Table 3$)$

AWSV, aortic distensibility and aortic strain have strong significant positive correlation with mitral annular plane systolic excursion (MAPSE) $(r=.61, r=.55, r=.41$ respectively, $p<0.01$ for each), Systolic mitral annular velocity $(\mathrm{Sm})(r=.64, r=$ $.48, r=.47$ respectively, $p<0.001$ for each), E/A ratio( $r=.49, r=.41, r=.39$ respectively, $p<0.05$ for each) and Em/Am ratio $(r=.60, r=.45, r=.42$ respectively, $\mathrm{p}<0.01$ for each) while the correlation was negative with Tei index $(r=-.61, r=-.5, r$ $=-.45$ respectively, $p<0.01$ for each), AHI $(r=-.55, r=-.43, r=-.39$ respectively, $p<0.05$ for each $)$ and BNP levels $(r$ $=-.67, r=-.59, r=-.5$ respectively, $p<0.001$ for each). Aortic distensibility was positively correlated with left ventricular ejection fraction $(r=.34, P<0.05)$ (see Table 4$)$.

AWSV showed strong negative correlation with left ventricular mass index $(r=-.47, P<0.001)$. In addition AWSV was positively correlated with left ventricular ejection fraction $(r=.37, P<0.05)$. The time taken by aortic wall to reach the peak systolic velocity (TS) showed positive correlation with MAPSE, Sm, E/A and Em/Am $(r=.46, r=.49, r=.35$ and $r=.41$ respectively, $p<0.05$ for each); while the correlation was negative with Tei index, AHI and BNP levels $(r=-.49, r=-.51$, $r=-.5$, respectively, $p<0.05$ for each) (see Table 4 ).

In analyses testing the reproducibility of AWSV, the interobserver and intraobserver variabilities were $4.2 \%$ and $3.1 \%$, respectively in pulsed-wave Doppler tissue imaging. Accordingly, AWSV has good limits for interobserver and intraobserver variabilities accounting for great reproducibility. Validation had been confirmed in previous studies ${ }^{[26,31]}$.

\section{Correlation of echocardiographic variables with BNP levels}

Taken together and considering the whole study population collectively, significant correlations $(p<0.01$ for all) were found between BNP levels and the examined echocardiographic variables. Positive correlations were observed between BNP and each of early transmitral $(\mathrm{E})$ to $\mathrm{Em}(\mathrm{E} / \mathrm{Em})$ ratio $(r=0.61)$ and LV end diastolic dimension $(r=0.63)$. Strong negative correlation was found between BNP and each of $\mathrm{Em}(r=-0.82), \operatorname{Sm}(r=-0.7), \mathrm{E} / \mathrm{A}(r=-0.67), \mathrm{Em} / \mathrm{Am}(r=-0.73)$ $\& \operatorname{LVEF}(r=-0.64)$ while a less negative but still significant correlation was observed between BNP and MAPSE ( $r=$ $-0.54)$.

There was a weak relationship between BNP levels and E/Em ratios in patients with normal LV function $(r=0.19)$. In contrast, the correlation was better in patients with diastolic dysfunction $(r=0.65)$.

Table 5. Multivariate regression analysis of impaired aortic function detected by Doppler tissue imaging among studied groups.

\begin{tabular}{llll}
\hline Variable & Odds ratio $(\mathbf{9 5 \%} \mathbf{C I})$ & Yates Corrected Chi & $\boldsymbol{p}$ value \\
\hline Age & $2.8(1.63,4.77)$ & 3.7 & $<0.05$ \\
OSAS & $2.9(1.59,3.37)$ & 3.9 & $<0.05$ \\
Hypertension & $2.19(1.35,4.1)$ & 3.4 & $<0.05$ \\
LVMI & $4.2(1.39,10.74)$ & 23.1 & $<0.001$ \\
LVEF\% & $1.33(0.51,1.47)$ & 0.04 & $>0.05$ \\
\hline
\end{tabular}

Note. LVEF, left ventricular ejection fraction; LVMI, left ventricular mass index; OSAS, obstructive sleep apnea syndrome

Using multivariate logistic regression analysis to estimate the predictors of impaired aortic elastic properties detected by Doppler tissue imaging (reduced AWSV), it was found that, age, OSAS, systemic hypertension and left ventricular mass index were independent predictors for impaired aortic function (see Table 5). A cut-off value of $6 \mathrm{~cm} / \mathrm{sec}$ for AWSV was utilized as indicator of impaired aortic mechanical function ${ }^{[26,31]}$. 


\section{Discussion}

Obstructive sleep apnea syndrome (OSAS) is a common sleep-related breathing disorder characterized by periodic reduction or cessation of breathing due to partial narrowing or complete collapse of the upper airways during sleep ${ }^{[32]}$. There is a large body of evidence showing that OSAS is associated with metabolic and CVS abnormalities, including insulin resistance, obesity, dyslipidemia, hypertension, coronary artery disease (CAD), arrhythmia, and congestive heart failure ${ }^{[33]}$. Increased activation of the sympathetic nervous system due to nocturnal hypopnea and apnea episodes and arousal reactions, respectively, is a pathophysiological hallmark of OSAS ${ }^{[33]}$.

In the current study, aortic elastic properties, longitudinal LV systolic function, regional and global LV diastolic function and BNP levels are found to be impaired in patients with OSAS irrespective of the presence systemic hypertension compared to control subjects and the impairment was more pronounced in patients having both disorders i.e patients with OSAS hypertension and systemic (group IV).

Our study shows that, DTI may facilitate the diagnosis of aortic stiffness and myocardial abnormality in patients with OSAS despite a preserved global function this because LV longitudinal fibers are abundant mainly in the subendocardium which is the location of any early cardiac pathology even before any clinical manifestation meanwhile the global LV function is still remaining intact. The diastolic filling pattern is known to be influenced by a number of factors, such as changes in pre- and after-load. On the contrary, DTI echocardiography analyses signals of high amplitude and low frequency and therefore allows direct measurement of the wall motion velocities that are relatively load independent compared to conventional echocardiography ${ }^{[17]}$.

In the current study, significant correlations were detected between aortic stiffness parameters (aortic strain, distensibility and AWSV) in one hand, and parameters of longitudinal LV systolic function, regional and global LV diastolic function, AHI and BNP levels, on the other hand and these correlations were detectable in all patients with OSAS, systemic hypertension, or both i.e OSAS alone in normotensive patients, identically affected all these parameters similar to systemic hypertension. Of note, AWSV has the strongest correlations with these variables compared to aortic strain and distensibility. Accordingly and based on these observational findings, it is believed that all cardiac, vascular and biochemical changes occur parallel to each other and in concordance during sustained effects of OSAS.

These finding are in close agreement with the findings of Tavil et al. ${ }^{[34]}$ and Kasikcioglu et al. ${ }^{[35]}$ who demonstrated that, OSAS affects aortic elasticity, LV longitudinal systolic function and regional and global diastolic functions independent from systemic hypertension.

It was interestingly found that these patients have increased LV mass index independent from systemic hypertension. These results are also concordant with the study of Hedner et al. ${ }^{[36]}$ who firstly reported increased LV wall thickness in normotensive patients with OSAS versus normotensive nonapneic subjects.

Wall movements in the aorta are synchronous but reverse with the heart ${ }^{[26]}$. Recently it has been demonstrated that the aorta is not a simple conduit for the distribution of blood but rather has a fundamental role in the function of the CVS system. Increased aortic stiffness and decreased distensibility, which indicate impairment in the elastic structure of the aorta, are associated with CAD and CAD risk factors ${ }^{[37]}$ and is one of the determinants of CVS morbidity and mortality ${ }^{[38]}$. Jelic et al. ${ }^{[39]}$ reported that, arterial stiffness increases during OSAS in the absence of measurable blood pressure changes. They also suggested that, arterial stiffness is associated with CVS outcomes of OSAS. Aortic stiffness measurements (aortic strain and distensibility), which were calculated from pulsatile changes in ascending aorta, are practically used for measuring the large arterial stiffness. Several reports ${ }^{[40,41]}$ have demonstrated that, there were good correlations between 
aortic function indices that were calculated from aortic root and indices derived from aortography and pulse wave analysis methods.

Our study demonstrated that, the percentage of patients having LV diastolic dysfunction is significantly higher in each patient group compared to control subjects and also more pronounced in patients having both OSAS and systemic hypertension (group IV) compared to those having only either OSAS (group III) or systemic hypertension (group II) alone. Many authors ${ }^{[35,36]}$ reported that, aortic elasticity and LV diastolic function are impaired in patients with OSAS. The findings of these studies are in close agreement with our results but, our study design aimed to evaluate aortic stiffness and LV function in patients with OSAS without systemic hypertension to clarify the impact of OSAS alone independent from systemic hypertension.

Although the exact mechanism of deterioration of myocardial contraction and relaxation is not known, mechanisms responsible for the increased aortic stiffness and LV abnormalities in OSAS may be various. Patients with OSAS may have an increased cardiac risk due to worsening of the relationship between myocardial oxygen demand and supply as a result of apnea-associated hypoxemia and activation of the autonomic nervous system and apnea-associated oxygen desaturation can trigger nocturnal myocardial ischemia ${ }^{[42]}$.

Hemodynamic fluctuations after the cyclical episodes of upper airway occlusion are supposed to be the major pathophysiologic link ${ }^{[34,43]}$. Nocturnal and intermittent changes of oxygenation cause sympathetic activation and deteriorate myocardial oxygen supplementation in OSAS ${ }^{[44]}$. Even though acute pathophysiologic changes occur during sleep period, it is believed that, hemodynamic and neurohumoral disturbances persist through 24 hours ${ }^{[34,45]}$. In addition, peripheral vascular resistance is increased followed by impairment in endothelial function as a result of release of the many vasoactive amines and endothelial function regulators. These vasoconstrictor changes may explain the early structural alterations in the aortic wall ${ }^{[46-48]}$. The other possible mechanism may be the increased afterload induced by LV myocardial structural changes together with the LV diastolic dysfunction. However, the opposite could well be true; the LV may structurally be changing to overcome the end-systolic wall stress caused by the afterload increase ${ }^{[49,50]}$. Thus, myocardial structural changes cause the gradual deterioration in systolic and diastolic function.

In multivariate logistic regression analysis, age, OSAS, systemic Hypertension and LV mass index were independent predictors for impaired aortic function detected by Doppler tissue imaging as reduction of AWSV. AWSV was found to be more accurate and reproducible than aortic strain and distensibility, with a cut-off value of $6 \mathrm{~cm} / \mathrm{sec}$ and was utilized as a good indicator of impaired aortic mechanical function. Validation had been confirmed in previous studies ${ }^{[26,31]}$.

\section{Study limitations}

M-mode, DTI and pulsed Doppler tracings cannot be obtained simultaneously, but meticulous care was taken to measure cycles with identical R-R intervals. Coronary angiography was not done in our study to rule out possibility of subclinical atherosclerosis and non-significant coronary lesions. The blood pressure was measured by cuff-sphygmomanometer from brachial artery which is non-invasive, practical and rapid method instead of invasive measurement from the ascending aorta.

Finally, the presence of inherent limitations, in pulsed wave Doppler tissue imaging technique, it includes the translational motion of the whole heart and the rotation movements that affect the measured velocities. However, the effect of these movements is minimal and does not dramatically affect DTI measurements except in patients with prominent cardiac translation movements. Another limitation is that, DTI system technique relies on the parallel alignment of the moving object examined. Thus, some of the observed differences in velocity between the walls could be accounted for angulations. 
These differences could be minimized by choosing myocardial regions of interest within 15-20 degrees of the axis of Doppler interrogation.

\section{Conclusion}

Aortic elasticity parameters (AWSV, aortic strain and distensibility), long axis LV systolic function, LV diastolic function parameters (derived by both conventional and tissue Doppler), Tei Index and BNP levels are all impaired in patients with OSAS, systemic hypertension or both. Accordingly subtle subclinical cardiac dysfunction is present in patients with OSAS independent from systemic hypertension, so routine echocardiographic screening of the above mentioned parameters in patients with OSAS with or without systemic hypertension is recommended, so as not to overlook some clinically silent cardiac functional deterioration.

\section{References}

[1] A report of the National Commission on Sleep Disorders Research. Wake Up America: A National Sleep Alert. Washington, DC: U.S. Government Printing Office. 1995.

[2] Young T, Peppard PE, Gottlieb DJ. Epidemiology of obstructive sleep apnea: a population health perspective. Am J Respir Crit Care Med. 2002; 165: 1217-39. PMid:11991871 http://dx.doi.org/10.1164/rccm.2109080

[3] Cheyne JA. A case of apoplexy, in which the fleshy part of the heart was converted into fat. Dublin Hospital Rep. 1818 ; 2: $216-23$.

[4] Sullivan CE, Issa FG, Berthon-Jones M, Eves L. Reversal of obstructive sleep apnea by continuous positive airway pressure applied through the nares. Lancet. 1981; 1: 862-5. http://dx.doi.org/10.1016/S0140-6736(81)92140-1

[5] Koskenvuo M, Kaprio J, Partinen M, Langinvainio H, Sarna S, Heikkila K. Snoring as a risk factor for hypertension and angina pectoris. Lancet. 1985; 1: 893-6. http://dx.doi.org/10.1016/S0140-6736(85)91672-1

[6] Hung J, Whitford EG, Parsons RW, Hillman DR. Association of sleep apnea with myocardial infarction in men. Lancet. 1990; 336: 261-4. http://dx.doi.org/10.1016/0140-6736(90)91799-G

[7] Peker Y, Kraiczi H, Hedner J, Loth S, Johansson A, Bende M. An independent association between obstructive sleep apnea and coronary artery disease. Eur Respir J. 1999; 14: 179-84. PMid:10489848 http://dx.doi.org/10.1034/j.1399-3003.1999.14a30.x

[8] Mooe T, Franklin KA, Wiklund U, Rabben T, Holmstrom K. Sleep-disordered breathing and myocardial ischemia in patients with coronary artery disease. Chest. 2000; 117: 1597-602. PMid:10858389 http://dx.doi.org/10.1378/chest.117.6.1597

[9] Leung RS, Bradley TD. Sleep apnea and cardiovascular disease. Am J Respir Crit Care Med. 2001; 164: 2147-65. PMid:11751180

[10] Young T, Peppard PE, Gottlieb DJ. Epidemiology of obstructive sleep apnea: a population health perspective. Am J Respir Crit Care Med. 2002; 165: 1217-39. PMid:11991871 http://dx.doi.org/10.1164/rccm.2109080

[11] Shahar E, Whitney CW, Redline S, Lee ET, Newman AB, Javier Nieto F. Sleep-disordered breathing and cardiovascular disease cross-sectional results of the sleep heart health study. Am J Respir Crit Care Med. 2001; 163: 19-25. PMid:11208620

[12] Kales A, Bixler EO, Cadieux RJ, Schneck DW, Shaw LC III, Locke TW. Sleep apnea in a hypertensive population. Lancet. 1984; 3: 1005-8. http://dx.doi.org/10.1016/S0140-6736(84)91107-3

[13] Williams AJ, Houston D, Finberg S, Lam C, Kinney JL, Santiago S. Sleep apnea syndrome and essential hypertension. Am J Cardiol. 1985; 55: 1019-22. http://dx.doi.org/10.1016/0002-9149(85)90738-6

[14] Hedner J, Ejnell H, Sellgren J. Is high and fluctuating muscle nerve activity in the sleep apnea syndrome of pathogenetic importance for the development of hypertension? J Hypertens. 1988; 6: 529-31.

[15] Laurent S, Boutouyrie P, Asmar R, Gautier I, Laloux B, Guize L. Aortic stiffness is an independent predictor of all-cause and cardiovascular mortality in hypertensive patients. Hypertension. 2001; 37: 1236-41. PMid:11358934

[16] Stefanadis C, Dernellis J, Tsiamis E, Stratos C, Diamantopoulos L, Michaelides A. Aortic stiffness as a risk factor for recurrent acute coronary events in patients with ischemic heart disease. Eur Heart J. 2000; 21: 390-6. PMid:10666353 http://dx.doi.org/10.1053/euhj.1999.1756

[17] Hulya A. Kasikcioglu, Levent Karasulu, Zeynep Tartan, Erdem Kasikcioglu, Caglar Cuhadaroglu, Nese Cam. Occult cardiac dysfunction in patients with obstructive sleep apnea syndrome revealed by tissue Doppler imaging. International Journal of Cardiology. 2007; 118: 203-205. PMid:16997399

[18] Yu CM, Sanderson JE, Shum IOL. Diastolic dysfunction and natriuretic peptides in systolic heart failure. Eur Heart J. 1996; 17: 1694-1702. PMid:8922918 http://dx.doi.org/10.1093/oxfordjournals.eurheartj.a014753 
[19] Maisel AS, Krishnaswamy P, Nowak RM. Rapid measurement of B-type natriuretic peptide in the emergency diagnosis of heart failure. N Engl J Med. 2002; 347: 161-167. PMid:12124404 http://dx.doi.org/10.1056/NEJMoa020233

[20] Schiller NB, Shah PM, Crawford M. Recommendations for quantitation of the left ventricle by 2-dimensional echocardiography. J Am Soc Echocardiogr. 1989; 2: 358-67. PMid:2698218

[21] Yvorchuk KJ, Davies RA, Chang KL. Measurement of left ventricular ejection fraction by acoustic quantification and comparison with radionuclide angiography. AM J Cardiol. 1994; 74: 1052-1056. http://dx.doi.org/10.1016/0002-9149(94)90858-3

[22] Mohamed Fahmy Elnoamany and Ayman Kilany Abdelhameed. Mitral annular motion as a surrogate for left ventricular function: Correlation with brain natriuretic peptide levels. Eur J Echocardiography. 2006; 7: 187-198. PMid:16046188 http://dx.doi.org/10.1016/j.euje.2005.05.005

[23] Lacombe F, Dart A, Dewar E. Arterial elastic properties in man: a comparison of echo-Doppler indices of aortic stiffness. Eur Heart J. 1992; 13: 1040-5. PMid:1505552

[24] Stefanadis C, Wooley CF, Bush CA. Aortic distensibility in post stenotic aortic dilatation: the effect of co-existing coronary artery disease. J Cardiol. 1988; 18: 78-82.

[25] Eduardo Casas Rojo, Jose' Luis Rodrigo, Leopoldo Pe'rez de Isla, Carlos Almerı'a, Nieves Gonzalo, Adalı'a Aubele, Rafael Cinza, Jose' Zamorano, Carlos Macaya. Disagreement between tissue Doppler imaging and conventional pulsed-wave Doppler in the measurement of myocardial performance index. Eur J Echocardiography. 2006; 7: 356-364. PMid:16198634 http://dx.doi.org/10.1016/j.euje.2005.08.004

[26] Hala Mahfouz Badran and Mohamed Elnoamany. Impact of type 2 diabetes mellitus on aortic elastic properties in normotensive diabetes: Doppler Tissue Imaging Study. J Am Soc Echocardiogr. 2006; 19: 1471-1481. PMid:17138032 http://dx.doi.org/10.1016/j.echo.2006.06.004

[27] Rechtschaffen A and Kales A. A manual of standardized terminology, techniques, and scoring system for sleep stages in human subjects. Los Angeles: Brain Information Service, VCLA; 1968.

[28] EEG arousals, scoring rules and examples: preliminary report from the sleep disorders atlas task force of the American Sleep Disorders Association. Sleep. 1992; 15: 173-84. PMid:11032543

[29] Dao Q, Krishnaswamy P, Kazanegra R. Utility of B-type natriuretic peptide (BNP) in the diagnosis of CHF in an urgent care setting. J Am Coll Cardiol. 2001; 37: 379-385. http://dx.doi.org/10.1016/S0735-1097(01)80006-1

[30] Saunders BD, Trapp RG: Basic and Clinical Biostatistics, 2nd Ed. Norwalk, CT: Appleton \& Lange, 1994.

[31] Eryol N, Topsakal R, Çiçek Y, Abaci A, Oguzhan A, Basar E, and Ergin A. Color Doppler tissue imaging in assessing the elastic properties of the aorta and in predicting coronary artery disease. Jpn Heart J. 2002; 43: 219-230. PMid:12227697 http://dx.doi.org/10.1536/jhj.43.219

[32] McNicholas WT, Bonsignore MR. Sleep apnea as an independent risk factor for cardiovascular disease: current evidence, basic mechanisms and research priorities. Eur Respir J. 2007; 29: 156-78. PMid:17197482 http://dx.doi.org/10.1183/09031936.00027406

[33] Micha T. Maeder a, Thomas Münzer, Hans Rickli, Otto D. Schoch ,Wolfgang Korte, Christoph Hürny , Peter Ammann. Association between heart rate recovery and severity of obstructive sleep apnea syndrome. Sleep Medicine. 2008; 9: 753-761. PMid:17980656 http://dx.doi.org/10.1016/j.sleep.2007.08.016

[34] Yusuf Tavil, Asiye Kanbay, Nihat S, Tansu Ulukavak Çiftçi, Adnan Abaci, M. Ridvan Yalçın, et al. The relationship between aortic stiffness and cardiac function in patients with obstructive sleep apnea, independently from systemic hypertension. J Am Soc Echocardiogr. 2007; 20: 366-372. PMid:17400115 http://dx.doi.org/10.1016/j.echo.2006.09.005

[35] Kasikcioglu HA, Karasulu L, Durgun E, Oflaz H, Kasikcioglu E, Cuhadaroglu C. Aortic elastic properties and left ventricular diastolic dysfunction in patients with obstructive sleep apnea. Heart Vessels. 2005; 20: 239-44. PMid:16314904 http://dx.doi.org/10.1007/s00380-005-0839-3

[36] Hedner J, Ejnell H, Caidahl K. Left ventricular hypertrophy independent of hypertension in patients with obstructive sleep apnea. J Hypertens. 1990; 8: 941-6. PMid:2174947 http://dx.doi.org/10.1097/00004872-199010000-00009

[37] Stefanadis C, Tsiamis E, Vlachopoulos C, Stratos C, Toutouzas K, Pitsavos C. Unfavorable effect of smoking on the elastic properties of the human aorta. Circulation. 1997; 95: 31-8. PMid:8994413

[38] Arnett DK, Evans GW, Riley WA. Arterial stiffness is a new cardiovascular risk factor. Am J Epidemiol. 1994; 140:669-82. PMid:7942769

[39] Jelic S, Bartels MN, Mateika JH, Ngai P, DeMeersman RE, Basner RC. Arterial stiffness increases during obstructive sleep apneas. Sleep. 2002; 25: 850-5. PMid:12489890

[40] Hundley WG, Kitzman DW, Morgan TM, Hamilton CA, Darty SN, Stewart KP. Cardiac cycle dependent changes in aortic area and distensibility are reduced in older patients with isolated diastolic heart failure and correlate with exercise intolerance. J Am Coll Cardiol. 2001; 38: 796-802. http://dx.doi.org/10.1016/S0735-1097(01)01447-4 
[41] Watanabe H, Ohtsuka S, Kakihana M, Sugishita Y. Coronary circulation in dogs with an experimental decrease in aortic compliance. J Am Coll Cardiol. 1993; 21: 1497-506. http://dx.doi.org/10.1016/0735-1097(93)90330-4

[42] Nagueh SF, Bachinski LL, Meyer D. Tissue Doppler imaging consistently detects myocardial abnormalities in patients with hypertrophic cardiomyopathy and provides a novel means for an early diagnosis before and independently of hypertrophy. Circulation. 2001; 104: 128-30. PMid:11447072

[43] Alchanatis M, Paradellis G, Pini H, Tourkohoriti G, Jordanoglou J. Left ventricular function in patients with obstructive sleep apnea syndrome before and after treatment with nasal CPAP. Respiration. 2000; 67: 367-71. PMid:10940788 http://dx.doi.org/10.1159/000029532

[44] Weiss JW, Launois SH, Anand A, Garpestad E. Cardiovascular morbidity in obstructive sleep apnea, Prog Cardiovasc Dis. 1999; 41: 367-76. PMid:10406330 http://dx.doi.org/10.1053/pcad.1999.0410367

[45] Carlson JT, Hedner J, Elam M, Ejnell H, Sellgren J, Wallin BG. Augmented resting sympathetic activity in awake patient with obstructive sleep apnea. Chest. 1993; 103: 763-8. PMid:8404098 http://dx.doi.org/10.1378/chest.103.6.1763

[46] Imadojemu VA, Gleeson K, Gray KS, Sinoway LI, Leuenberger UA. Obstructive apnea during sleep is associated with peripheral vasoconstriction. Am J Respir Crit Care Med. 2002; 165: 61-6. PMid:11779731

[47] Takahashi S, Nakamura Y, Nishijima T, Sakurai S, Inoue H. Essential roles of angiotensin II in vascular endothelial growth factor expression in sleep apnea syndrome. Respir Med. 2005; 99: 1125-31. PMid:16085213 http://dx.doi.org/10.1016/j.rmed.2005.02.027

[48] Kraiczi H, Caidahl K, Samuelsson A, Peker Y, Hedner J. Impairment of vascular endothelial function and left ventricular filling: association with the severity of apnea induced hypoxemia during sleep. Chest. 2001; 119: 1085-91. PMid:11296174 http://dx.doi.org/10.1378/chest.119.4.1085

[49] Stradling J, Davies JO. Sleep apnea and hypertension. Sleep. 1997; 20: 789-93. PMid:9406330

[50] Guilleminault C, Robinson A. Sleep-disordered breathing and hypertension: past lessons, future directions. Sleep. 1997; 20: 806-11. PMid:9406332 